DOI 10.37882/2223-2982.2021.02.39

\title{
ДИНАМИКА ПОКАЗАТЕЛЕЙ ФИЗИЧЕСКОГО РАЗВИТИЯ У ДЕВОЧЕК В ВОЗРАСТЕ 7 - 10 ЛЕТ В ХУДОЖЕСТВЕННОЙ ГИМНАСТИКЕ
}

\section{DYNAMICS OF PHYSICAL DEVELOPMENT INDICATORS IN GIRLS AGED 7-10 YEARS IN RHYTHMIC GYMNASTICS}

L. Shuvalova

Summary: The purpose of this study was to update and form statistically significant indicators that characterize the physical development of a child aged 7-10 years who is engaged in sports training in the sport of rhythmic gymnastics. The research methods used are anthropometry (measurement and recording of total body size), indices of physical development (Brugsch Index, Bouchard Index, Verveck Index, Rohrer Index), methods of mathematical statistics. The results of the study included data on the growth rate of physical development indicators during the calendar year in girls aged 7-10 years. Statistically significant patterns were revealed. Features of physical development of girls of 7-10 years are caused by the inclusion of children in the system of sports training. The dynamics of changes can be most clearly assessed by the growth rate of development indicators, as well as by using the results of calculations of biological development indices.

Keywords: physical development, rhythmic gymnastics, primary school age, body length, weight, chest circumference.
Шувалова Лилия Сергеевна

Аспирант, ФГБУ «Федеральный научный чентр физической культуры и спорта» (ФГБУ ФНЦ ВНИИФК), Москва

lilia9292@mail.ru

Аннотация: Целью настоящего исследования была актуализация и формирование статистически значимых показателей, характеризующих физическое развитие ребенка в возрасте 7-10 лет, осуществляющего спортивную подготовку по виду спорта художественная гимнастика. В качестве методов исследования использована антропометрия (измерение и фиксация тотальных размеров тела), индексы физического развития (Индекс Бругша, Индекс Бушара Индекс Вервека, Индекс Рорера), методы математической статистики. В результатах исследования были полученные данные о темпах прироста показателей физического развития в течение календарного года у девочек 7 - 10 лет. Выявлены статистически значимые закономерности. Особенности физического развития девочек 7 - 10 лет обусловлены включенностью детей в систему спортивной подготовки. Наиболее ярко динамику изменений возможно оценить по темпам прироста показателей развития, а также при использовании результатов расчетов индексов биологического развития.

Ключевые слова: физическое развитие, художественная гимнастика, младший школьный возраст, длина тела, масса, окружность грудной клетки.

\section{Введение}

$\mathrm{B}$ соответствии с целями Федерального стандарта спортивной подготовки по виду спорта художественная гимнастика, мероприятия направленные на контроль состояния спортсменов являются обязательным компонентом системы спортивной подготовки на каждом из её этапов [5]. В возрастной период от 7 до 10 лет происходят сложнейшие морфофункциональные преобразования органов и систем организма. Данные преобразования протекают гетерохронно [6] и требуют постоянного мониторинга с целью формирования и укрепления здоровья, а также развития моторного потенциала и соревновательной успешности. Материалы и методы. В настоящем исследовании приняли участие 80 спортсменок (2010 - 2013 г.р.), проходящих спортивную подготовку на начальном и тренировочном этапе спортивной подготовки в Региональной детской общественной организации «Детский молодежный спортивный клуб «ФОРС», Москва. В программу антропометрических исследований были включены измерения тотальных размеров тела, к которым относятся основные показа- тели физического развития человека - длина тела (см), обхват грудной клетки (см) масса тела (кг) [1]. На основе полученных данных о тотальных размерах тела были высчитаны индексы, характеризующие физическое развитие: индекс Бругша (для оценки телосложения ребёнка); индекс Бушара (для определения соматотипа), индекса Вервека (для определения соматотипа), Индекс Рорера (для определения гармоничности развития). Высчитывались и анализировались темпы базисного роста для каждого показателя по состояния на август 2020 г. и январь 2021 г. для каждой возрастной группы. Статистическая значимость исследуемых признаков определялась при помощи коэффициента корреляции Пирсона.

\section{ヘитературный образ}

Традиционно к морфофункциональным свойствам организма относят длину и массу тела, окружность грудной клетки (ОГК) $[2,3,4,6,7]$. Данные компоненты и их соотношение являются маркерами физического развития организма [8]. Соотношение данных параметров обусловлено, как и генетическими, так и средовыми 
факторами, причем одной из ведущих переменных, обуславливающий средовое влияние является физкультурно-спортивная деятельность, что подтверждается исследованиями отечественных и зарубежных специалистов $[8,9]$.

В ходе исследования были вычислены усреднённые значения показателей физического развития (тотальные размеры тела) для каждой возрастной группы юных гимнасток (2013 г.р., 2012 г.р., 2011 г.р., 2010 г.р.), общей численностью 60 человек и высчитаны средние темпы базисного прироста показателей физического развития по результатам трех обследований - февраль 2020, август 2020 и январь 2021 (таблица 1,2).

На основе полученных данных были рассчитаны индексы, отражающие физическое развитие.

Полученные данных представлены в таблицах 3-4.

\section{Результаты}

В группе девочек 2013 г.р. (n=20) были выявлены значимые сильные положительные взаимосвязи между показателями длины тела (см) в феврале 2020 и в августе 2020 ( $\left.r=0.953^{* * *}, \mathrm{p}<0,001\right)$. Между показателями длины тела в феврале 2020 и январе 2021 также существуют значимые сильные положительные взаимосвязи $\left(r=0.829^{* * *}, p<0,001\right)$. Были выявлены значимые сильные положительные взаимосвязи между показателями длины тела (см) в августе 2020 и в январе 2021 ( $r=0.866^{* * *}$, $p<0,001)$

В группе девочек 2012 г.р. (n=20) были выявлены статистически значимые сильные положительные взаимосвязи между показателями длины тела (см) в феврале 2020 и в августе 2020 ( $\left.r=0.976^{* * *}, p<0,001\right)$. Между показателями длины тела в феврале 2020 и январе 2021 также существуют значимые сильные положительные взаимосвязи $\left(r=0.943^{* * *}, p<0,001\right)$. Достоверно значимые показатели изменения длины тела были определены между измерениями в августе 2020 и январе 2021 ( $\left.r=0.967^{* * *}, p<0,001\right)$.

В группе девочек 2011 г.р. (n=20) были выявлены статистически значимые сильные положительные взаимосвязи между показателями длины тела (см) в феврале 2020 и в январе 2021 ( $\left.r=0.913^{* * *}, \mathrm{p}<0,001\right)$. Между показателями длины тела в феврале 2020 и в августе 2021 также существуют значимые сильные положительные взаимосвязи ( $\left.r=0.936^{* * *}, \mathrm{p}<0,001\right)$.Однако, в период с февраля 2020 по август 2020 выявленные изменения показателя длины тела (см) остаются достоверно значимыми, характеризуясь средней положительной взаимосвязью $\left(r=0.672^{* *}, p<0,01\right)$.

В группе девочек 2010 г.р. (n=20) были выявлены статистически значимые сильные положительные взаимосвязи между показателями длины тела (см) в августе 2020 и в январе 2021 ( $\left.r=0.838^{* * *}, p<0,001\right)$.

Таблица 1.

Динамика показателей тотальных размеров тела у девочек в возрасте 7-10 лет, занимающихся художественной гимнастикой

\begin{tabular}{|c|c|c|c|c|c|c|c|c|c|c|c|c|c|}
\hline \multirow{3}{*}{ 운 } & \multirow{3}{*}{ 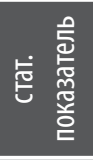 } & \multicolumn{3}{|c|}{ длина тела, см } & \multicolumn{3}{|c|}{ темп базисного прироста \% } & \multicolumn{3}{|c|}{ обхват грудной клетки, см } & \multicolumn{3}{|c|}{ темп базисного прироста \% } \\
\hline & & фев. & авг. & янВ. & авг. & янв. & 읕 & фев. & авг. & янв. & авг. & янв. & 을 。 \\
\hline & & 2020 & 2020 & 2021 & 2020 & 2021 & $\dot{8}^{\circ}$ & 2020 & 2020 & 2021 & 2020 & 2021 & $\dot{8}^{\circ}$ \\
\hline \multirow{4}{*}{$\bar{\sim}$} & M & 116,44 & 118,08 & 122,01 & \multirow{4}{*}{1,42} & \multirow{4}{*}{4,79} & \multirow{4}{*}{3,10} & 59,10 & 60,19 & 62,89 & \multirow{4}{*}{1,84} & \multirow{4}{*}{4,50} & \multirow{4}{*}{3,17} \\
\hline & 0 & 1,97 & 1,79 & 1,78 & & & & 0,96 & 1,19 & 1,23 & & & \\
\hline & $\pm m$ & 0,44 & 0,40 & 0,40 & & & & 0,21 & 0,27 & 0,28 & & & \\
\hline & V & 1,69 & 1,52 & 1,46 & & & & 1,62 & 1,98 & 1,96 & & & \\
\hline \multirow{4}{*}{ ָั } & M & 126,15 & 128,69 & 131,26 & \multirow{4}{*}{2,01} & \multirow{4}{*}{4,07} & \multirow{4}{*}{3,04} & 63,02 & 64,77 & 67,26 & \multirow{4}{*}{2,79} & \multirow{4}{*}{6,75} & \multirow{4}{*}{4,77} \\
\hline & $\sigma$ & 3,56 & 4,00 & 3,23 & & & & 1,39 & 1,62 & 2,08 & & & \\
\hline & $\pm m$ & 0,80 & 0,89 & 0,72 & & & & 0,31 & 0,36 & 0,47 & & & \\
\hline & V & 2,82 & 3,11 & 2,46 & & & & 2,21 & 2,51 & 3,09 & & & \\
\hline \multirow{4}{*}{$\overline{\check{\nu}}$} & $M$ & 131,30 & 133,34 & 135,55 & \multirow{4}{*}{1,56} & \multirow{4}{*}{3,24} & \multirow{4}{*}{2,40} & 63,95 & 65,18 & 67,65 & \multirow{4}{*}{1,93} & \multirow{4}{*}{5,81} & \multirow{4}{*}{3,87} \\
\hline & 0 & 2,71 & 2,69 & 2,49 & & & & 2,48 & 2,40 & 2,55 & & & \\
\hline & $\pm m$ & 0,61 & 0,60 & 0,56 & & & & 0,55 & 0,54 & 0,57 & & & \\
\hline & V & 2,07 & 2,02 & 1,84 & & & & 3,87 & 3,68 & 3,77 & & & \\
\hline \multirow{4}{*}{ 음 } & $M$ & 133,66 & 136,01 & 137,83 & \multirow{4}{*}{1,76} & \multirow{4}{*}{1,34} & \multirow{4}{*}{1,55} & 68,50 & 69,83 & 71,04 & \multirow{4}{*}{1,93} & \multirow{4}{*}{3,71} & \\
\hline & $\sigma$ & 1,35 & 1,50 & 1,51 & & & & 1,53 & 1,71 & 1,71 & & & 70 \\
\hline & $\pm m$ & 0,30 & 0,34 & 0,34 & & & & 0,34 & 0,38 & 0,38 & & & $L, 8 L$ \\
\hline & V & 1,01 & 1,10 & 1,09 & & & & 2,24 & 2,46 & 2,40 & & & \\
\hline
\end{tabular}


Таблица 2.

Динамика показателей тотальных размеров тела у девочек в возрасте 7-10 лет, занимающихся художественной гимнастикой

\begin{tabular}{|c|c|c|c|c|c|c|c|}
\hline \multirow{3}{*}{ г.р. } & \multirow{3}{*}{ 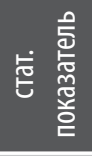 } & \multicolumn{3}{|c|}{ масса тела, кг } & \multicolumn{3}{|c|}{ темп базисного прироста \% } \\
\hline & & фев. & авг. & ЯНВ. & авг. & ЯНВ. & 을 \\
\hline & & 2020 & 2020 & 2021 & 2020 & 2021 & $\dot{8}^{\circ}$ \\
\hline \multirow{4}{*}{2013} & M & 18,39 & 19,56 & 20,62 & 6,37 & 12,11 & \multirow{4}{*}{9,24} \\
\hline & 0 & 1,05 & 1,12 & 1,36 & 1,48 & 2,99 & \\
\hline & $\pm \mathrm{m}$ & 0,23 & 0,25 & 0,30 & 0,33 & 0,67 & \\
\hline & V & 5,70 & 5,73 & 6,61 & 23,16 & 24,66 & \\
\hline \multirow{4}{*}{2012} & M & 22,03 & 23,74 & 24,08 & 7,92 & 9,49 & \multirow{4}{*}{8,71} \\
\hline & $\sigma$ & 1,45 & 1,12 & 1,07 & 4,00 & 4,50 & \\
\hline & $\pm m$ & 0,32 & 0,25 & 0,24 & 0,89 & 1,01 & \\
\hline & V & 6,58 & 4,71 & 4,43 & 76,49 & 43,06 & \\
\hline \multirow{4}{*}{2011} & M & 24,57 & 25,54 & 26,87 & 3,99 & 9,43 & \multirow{4}{*}{6,71} \\
\hline & $\sigma$ & 1,10 & 1,00 & 1,13 & 3,05 & 4,06 & \\
\hline & $\pm m$ & 0,25 & 0,22 & 0,25 & 0,68 & 0,91 & \\
\hline & V & 4,49 & 3,92 & 4,20 & 76,49 & 43,06 & \\
\hline \multirow{4}{*}{2010} & $M$ & 25,85 & 27,67 & 29,73 & 7,17 & 7,55 & \multirow{4}{*}{7,36} \\
\hline & 0 & 1,45 & 1,38 & 1,49 & 4,73 & 4,49 & \\
\hline & $\pm m$ & 0,33 & 0,31 & 0,33 & 1,06 & 1,00 & \\
\hline & V & 5,63 & 5,00 & 5,00 & 65,97 & 59,49 & \\
\hline
\end{tabular}

Таблица 3.

Показатели индексов физического развития у девочек в возрасте 7-10 лет, занимающихся художественной гимнастикой

\begin{tabular}{|c|c|c|c|c|c|c|c|c|c|c|c|c|c|}
\hline \multirow{3}{*}{ 운 } & \multirow{3}{*}{ 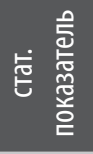 } & \multicolumn{3}{|c|}{ индекс Бругша \% } & \multicolumn{3}{|c|}{ темп базисного прироста \% } & \multicolumn{3}{|c|}{ индекс Бругша \% } & \multicolumn{3}{|c|}{ темп базисного прироста \% } \\
\hline & & фев. & авг. & ЯНВ. & авг. & ЯНВ. & 읕 。 & фев. & авг. & ЯНВ. & авг. & ЯНВ. & 읕 。 \\
\hline & & 2020 & 2020 & 2021 & 2020 & 2021 & $\dot{8}^{\circ}$ & 2020 & 2020 & 2021 & 2020 & 2021 & 은 \\
\hline \multirow{4}{*}{$\stackrel{m}{\check{D}}$} & M & 50,76 & 50,83 & 51,54 & \multirow{4}{*}{0,13} & \multirow{4}{*}{1,55} & \multirow{4}{*}{0,84} & 15,79 & 16,56 & 16,89 & \multirow{4}{*}{4,89} & \multirow{4}{*}{6,97} & \multirow{4}{*}{5,93} \\
\hline & $\sigma$ & 0,54 & 0,91 & 0,62 & & & & 0,68 & 0,75 & 0,90 & & & \\
\hline & $\pm \mathrm{m}$ & 0,12 & 0,20 & 0,14 & & & & 0,15 & 0,17 & 0,20 & & & \\
\hline & V & 1,06 & 1,79 & 1,21 & & & & 4,29 & 4,52 & 5,30 & & & \\
\hline \multirow{4}{*}{ ָ̃ } & M & 49,98 & 50,35 & 51,25 & \multirow{4}{*}{0,76} & \multirow{4}{*}{2,58} & \multirow{4}{*}{1,67} & 17,45 & 18,44 & 18,34 & \multirow{4}{*}{5,81} & \multirow{4}{*}{5,22} & \multirow{4}{*}{5,51} \\
\hline & 0 & 0,54 & 1,29 & 1,23 & & & & 0,81 & 0,53 & 0,53 & & & \\
\hline & $\pm \mathrm{m}$ & 0,12 & 0,29 & 0,27 & & & & 0,18 & 0,12 & 0,12 & & & \\
\hline & V & 1,08 & 2,56 & 2,40 & & & & 4,62 & 2,89 & 2,87 & & & \\
\hline \multirow{4}{*}{$\overline{\check{D}}$} & M & 48,93 & 49,04 & 50,04 & \multirow{4}{*}{0,23} & \multirow{4}{*}{2,31} & \multirow{4}{*}{1,27} & 18,71 & 19,15 & 19,82 & \multirow{4}{*}{2,40} & \multirow{4}{*}{6,00} & \multirow{4}{*}{4,20} \\
\hline & 0 & 0,54 & 1,28 & 1,29 & & & & 0,57 & 0,46 & 0,71 & & & \\
\hline & $\pm m$ & 0,12 & 0,29 & 0,29 & & & & 0,13 & 0,10 & 0,16 & & & \\
\hline & V & 1,10 & 2,61 & 2,59 & & & & 3,03 & 2,41 & 3,60 & & & \\
\hline \multirow{4}{*}{ 윰 } & $M$ & 51,25 & 51,26 & 51,54 & \multirow{4}{*}{0,02} & \multirow{4}{*}{0,57} & \multirow{4}{*}{0,30} & 19,33 & 20,34 & 21,56 & \multirow{4}{*}{5,32} & \multirow{4}{*}{11,73} & \\
\hline & $\sigma$ & 0,54 & 1,19 & 1,11 & & & & 1,00 & 0,87 & 0,91 & & & 857 \\
\hline & $\pm m$ & 0,12 & 0,27 & 0,25 & & & & 0,22 & 0,20 & 0,20 & & & 0,52 \\
\hline & V & 1,05 & 2,33 & 2,15 & & & & 5,16 & 4,29 & 4,23 & & & \\
\hline
\end{tabular}


Таблица 4.

Показатели индексов физического развития у девочек в возрасте 7-10 лет, занимающихся художественной гимнастикой

\begin{tabular}{|c|c|c|c|c|c|c|c|c|c|c|c|c|c|}
\hline \multirow{3}{*}{ 운 } & \multirow{3}{*}{ 它惫 } & \multicolumn{3}{|c|}{ Индекс Вервека } & \multicolumn{3}{|c|}{ темп базисного прироста \% } & \multicolumn{3}{|c|}{ Индекс Рорера } & \multicolumn{3}{|c|}{ темп базисного прироста \% } \\
\hline & & фев. & авг. & янВ. & авг. & янВ. & 은 & фев. & авг. & ЯнВ. & авг. & янВ. & \\
\hline & & 2020 & 2020 & 2021 & 2020 & 2021 & 요 $^{\circ}$ & 2020 & 2020 & 2021 & 2020 & 2021 & $\dot{8}^{\circ}$ \\
\hline \multirow{4}{*}{$\tilde{\frac{m}{\sigma}}$} & $M$ & 1,21 & 1,19 & 1,17 & \multirow{4}{*}{$-2,07$} & \multirow{4}{*}{$-3,49$} & \multirow{4}{*}{$-2,78$} & 11,64 & 11,87 & 11,34 & \multirow{4}{*}{1,99} & \multirow{4}{*}{$-2,57$} & \multirow{4}{*}{$-0,29$} \\
\hline & $\sigma$ & 0,02 & 0,02 & 0,02 & & & & 0,34 & 0,38 & 0,36 & & & \\
\hline & $\pm m$ & 0,00 & 0,01 & 0,01 & & & & 0,08 & 0,08 & 0,08 & & & \\
\hline & V & 1,56 & 1,96 & 2,12 & & & & 2,90 & 3,17 & 3,21 & & & \\
\hline \multirow{4}{*}{ 芩 } & M & 1,18 & 1,15 & 1,14 & \multirow{4}{*}{$-2,69$} & \multirow{4}{*}{$-3,44$} & \multirow{4}{*}{$-3,06$} & 10,98 & 11,16 & 10,66 & \multirow{4}{*}{1,72} & \multirow{4}{*}{$-2,81$} & \multirow{4}{*}{$-0,55$} \\
\hline & 0 & 0,03 & 0,02 & 0,02 & & & & 0,53 & 0,72 & 0,49 & & & \\
\hline & $\pm \mathrm{m}$ & 0,01 & 0,00 & 0,00 & & & & 0,12 & 0,16 & 0,11 & & & \\
\hline & V & 2,24 & 1,69 & 1,72 & & & & 4,87 & 6,43 & 4,62 & & & \\
\hline \multirow{4}{*}{$\bar{i}$} & $M$ & 1,16 & 1,15 & 1,12 & \multirow{4}{*}{$-1,20$} & \multirow{4}{*}{$-3,77$} & \multirow{4}{*}{$-2,49$} & 10,86 & 10,77 & 10,79 & \multirow{4}{*}{$-0,70$} & \multirow{4}{*}{$-0,50$} & \multirow{4}{*}{$-0,60$} \\
\hline & 0 & 0,03 & 0,02 & 0,03 & & & & 0,39 & 0,36 & 0,52 & & & \\
\hline & $\pm \mathrm{m}$ & 0,01 & 0,01 & 0,01 & & & & 0,09 & 0,08 & 0,12 & & & \\
\hline & $\mathrm{V}$ & 2,17 & 1,95 & 2,57 & & & & 3,57 & 3,30 & 4,82 & & & \\
\hline \multirow{4}{*}{ 음 } & $M$ & 1,11 & 1,09 & 1,06 & \multirow{4}{*}{$-2,28$} & \multirow{4}{*}{$-4,86$} & \multirow{4}{*}{$-3,57$} & 10,82 & 10,99 & 11,35 & \multirow{4}{*}{1,72} & \multirow{4}{*}{5,06} & \\
\hline & $\sigma$ & 0,03 & 0,02 & 0,03 & & & & 0,51 & 0,39 & 0,38 & & & \\
\hline & $\pm \mathrm{m}$ & 0,01 & 0,01 & 0,01 & & & & 0,11 & 0,09 & 0,08 & & & 3,39 \\
\hline & V & 2,64 & 2,10 & 2,50 & & & & 4,75 & 3,56 & 3,33 & & & \\
\hline
\end{tabular}

В группе девочек 2011 г.р. (n=20) были выявлены статистически значимые сильные положительные взаимосвязи между показателями длины тела (см) в феврале 2020 и в январе 2021 ( $\left.r=0.913^{* * *}, \mathrm{p}<0,001\right)$. Между показателями длины тела в феврале 2020 и в августе 2021 также существуют значимые сильные положительные взаимосвязи ( $\left.r=0.936^{* * *}, \mathrm{p}<0,001\right)$.Однако, в период с февраля 2020 по август 2020 выявленные изменения показателя длины тела (см) остаются достоверно значимыми, характеризуясь средней положительной взаимосвязью $\left(r=0.672^{* *}, p<0,01\right)$.

В группе девочек 2010 г.p. (n=20) были выявлены статистически значимые сильные положительные взаимосвязи между показателями длины тела (см) в августе 2020 и в январе $2021\left(r=0.838^{* * *}, p<0,001\right)$.

По сравнению с измерениями, проведенными в феврале 2020 года, уже к августу темп прироста показателя «обхват грудной клетки, см» увеличился во всех 4 группах гимнасток, однако наибольший прирост зафиксирован у девочек 2012 г.р. (2,79\%), наименьший прирост обнаружен в группе девочек 2011 и 2010 г.р. (1,93\%).

Показатель «обхват грудной клетки, см» характеризуется значительным темпом прироста. Наибольшее усредненное значение темпа прироста к январю 2021 зафиксировано у девочек 2012 г.р. (6,75\%), наименьший показатель в группе 2010 г.р. и составил 3,71\%.
В группе девочек 2013 г.р. в период с февраля по август 2020 изменения показателя «обхват грудной клетки, см», характеризуются сильной положительной взаимосвязью $\left(r=0.827^{* * *}, p<0,001\right)$. Однако, с февраля и августа 2020 по январь 2021 изменения показателя «обхват грудной клетки, см», характеризуются взаимосвязью уже средней силы $\left(r=0.674^{* *}, p<0,01\right.$ и $\left.r=0.576^{* *}, p<0,01\right)$ соответственно .

В группе девочек 2012 г.р. $(\mathrm{n}=20)$ были выявлены средние положительные взаимосвязи между показателями обхватов в период с февраля по август 2020 ( $r=0.684^{* * *}$, $\mathrm{p}<0,001)$, так и в обхватов в период с февраля по январь 2021 ( $\left.r=0.584^{* *}, p<0,01\right)$. Однако, если рассматривать как изменил свое значение данный показатель в период с августа 2020 по январь 2021, то взаимосвязь приобрела значимый сильный характер $\left(r=0.857^{* * *}, p<0,001\right)$.

В группе девочек 2011 г.p. (n=20) были выявлены значимые сильные положительные взаимосвязи между обхватами в период с февраля по август 2020 ( $\mathrm{r}=0.951^{* * *}$, $\mathrm{p}<0,001)$ и с февраля 2020 по январь 2021 ( $r=0.798^{* * *}$, р<0,001). С августа 2020 по январь 2021 выявлены значимые сильные положительные взаимосвязи изменения показателя обхвата грудной клетки $\left(r=0.82^{* * *}, p<0,001\right)$.

В группе девочек 2010 г.р. (n=20) были выявлены значимые сильные положительные взаимосвязи между обхватами в период с февраля по август 2020 ( $r=0.931^{* * *}$, 
$\mathrm{p}<0,001)$ и в период с февраля 2020 по январь 2021 $\left(r=0.836^{* * *}, p<0,001\right)$. С августа 2020 по январь 2021 выявлены значимые сильные положительные взаимосвязи изменения показателя обхвата грудной клетки $\left(r=0.846^{* * *}, p<0,001\right)$.

Исследуя, показатель «масса тела, кг» было выявлено, что в августе 2020 года наибольший процент темпа прироста наблюдался у девочек 2010 г.р. (7,17\%). Наименьший темп базисного прироста наблюдался у девочек 2010 г.р. (3,99\%). В январе 2021 года наибольший процент темпа прироста наблюдался у девочек 2013 г.р. (12,11\%). Наименьший темп базисного прироста наблюдался у девочек 2010 г.р. (7,55\%).

В группе девочек 2013 г.р. в период с августа 2020 по январь 2021 изменения показателя «масса тела, кг», характеризуются сильной положительной взаимосвязью $\left(r=0.829^{* * *}, p<0,001\right)$.

В группе девочек 2012 г.р. в период с февраля по август 2020 изменения показателя «масса тела, кг», характеризуются сильной положительной взаимосвязью $\left(r=0.829^{* * *}, p<0,001\right)$, аналогичная тенденция сохраняется с февраля 2020 по январь 2021 ( $\left.r=0.772^{* * *}, p<0,001\right)$. Существуют значимые сильные положительные взаимосвязи между изменениями показателя «масса тела, кг» В период с августа 2020 по январь 2021 ( $r=0.975^{* * *}$, $\mathrm{p}<0,001)$.

В группе девочек 2011 г.р. в период с февраля по август 2020 изменения показателя «масса тела, кг», характеризуются средним положительным уровнем взаимосвязи $\left(r=0.617^{* *}, p<0,01\right)$. Однако, в период с августа 2020 по январь 2021 зафиксированы уже значимые сильные положительные взаимосвязи $\left(r=0.716^{* * *}, p<0,001\right)$.

В группе девочек 2010 г.р. в период с февраля по август 2020 изменения показателя «масса тела, кг», характеризуются средним положительным уровнем взаимосвязи $\left(r=0.685^{* * *}, p<0,001\right)$, как и в период с августа 2020 по январь $2021\left(\mathrm{r}=0.647^{* *}, \mathrm{p}<0,01\right)$.

Пропорциональность развития грудной клетки исчислялась с помощью индекса Бругша. Отставание темпов прироста было выявлено в феврале 2020 г. у девочек в группах 2012 и 2011 г.р. Данная тенденция сохранилась и по анализам результатов измерений в августе 2020 года в группе девочек 2011 г.р. Однако, именно в группе девочек 2011 г.р. был зафиксирован самый высокий темп базисного прироста к январю 2021 и составил 1,27\%.

Масса тела юных спортсменок оценивалась с помощью индекса Бушара. Наибольший темп прироста от первоначального измерения зафиксирован в группе девочек 2010 г.р. и составил по состоянию на август 2020 года 5,32\%, по состоянию на январь 2021 года 11,7\%. Наименьший показатель базисного темпа прироста индекса Бушара замечен в группе девочек 2011 г.р. т составил 2,4\% по состоянию на август 2020 года. По состоянию на январь 2021 года самый низкий показатель базисного темпа прироста зафиксирован у девочек 2011 г.р. и составил $5,2 \%$.

Гармоничность физического развития была оценена при помощи индекса Вервека. Значение величины данного индекса в диапазоне от 1,25 - 0,85 единиц отражает гармоничное развитие ребенка и указывает на мезоморфный тип телосложения. Однако, при оценке данного индекса у юных гимнасток в возрасте 7-10 лет была выявлена тенденцию к отрицательному базисному приросту показателя. Снижение темпа базисного прироста обнаружено у девочек 2010 г.р. и составило $-4,8 \%$ по состоянию на январь 2021 года.

Физическое развитие юных гимнасток в возрасте 7-10 лет было оценено по средству индекса Рорера. У девочек 2012 г.р. наблюдался наиболее значительный отрицательный темп базисного прироста показателя по состоянию на январь 2021 года (-2,81\%). Наиболее высокий темп базисного прироста индекса Рорера наблюдается у девочек 2010 г.р. и по состоянию на январь 2021 составил $5,6 \%$.

\section{ОбсужАение}

Анализ показателей индекса Бругша свидетельствует о гармоничности физического развития и пропорциональность грудной клетки юных спортсменов. Однако полученные индексы соответствует нижней грани нормы характеризуются в качестве маркера астенического типа телосложения, что особо заметно начиная с группы спортсменок 2011 г.р. (т.е. 9-10 лет).

Анализируя расчетные значения индексов физического развития, было обнаружено, что у девочек в возрасте 7-10 лет несколько снижены показатели индекса Бушара. Полученные данные отражают тенденцию роста данного показателя у всех возрастных групп, однако зафиксированные значения свидетельствуют о недостаточной массе тела и соответствуют астеническому типу телосложения.

Расчетные значения для индекса Вервека соответствуют диапазону значений, характерному мезоморфии и отражают гармоничное развитие ребенка. Однако во всех возрастных группах зафиксировано снижение данного показателя по мере спортивного стажа и соответствие нижней грани нормального распределения значений.

Расчетные значения для Индекс Рорера отражают гармоничное развитие ребенка. Однако, примерно в 
возрасте 8-9 лет наиболее значительное снижение данного показателя. Однако в возрасте 10-11 лет данный показатель снова возрастает и остается в пределах нормальных значений.

\section{Зак^ючение}

Особенности физического развития девочек 7 - 10 лет обусловлены включенностью детей в систему спортивной подготовки. Наиболее ярко динамику изменений возможно оценить по темпам базисного прироста показателей развития, а также при использовании результатов расчетов индексов биологического развития.

Гармоничность физического развития девочек в возрасте 7-10 лет соответствует нижней грани нормы, утвержденной для данной возрастной группы. Однако в возрасте 8-9 лет, что соответствует возрасту перехода с одного этапа подготовки на другой наблюдается значительный дисбаланс, обусловленный интенсификацией процесса подготовки. В данный возрастной период уже формируются более яркие соматотипические проявления конституциональной принадлежности спортсменок - астеникам. В целом анализ данных продемонстрировал сниженные значения показателей физического развития детей с явным замедлением в переходный период с этапа на этап, наряду с явной тенденцией к восстановлению нормальных значений к возрасту десяти лет. Данная тенденция обусловлена стрессорным воздействием изменившихся параметров тренировочных и соревновательных воздействии (по объему и интенсивности), вследствие чего организму юных спортсменов необходимо было длительное время (в среднем от полугода) для адаптации к предлагаемым нагрузкам и функционированию условиях в новой морфологической ситуации.

\section{ЛИТЕРАТУРА}

1. Абрамова Т.Ф., Никитина Т.М., Полфунтикова и др. Влияние систематических занятий спортом на физическое развитие и физическую подготовленность детей 6-10 лет. Вестник Московского университета. Сер. 23: Антропология. 2019. № 3. С. 5-14.

2. Гужаловский А.А. Проблема «критических» периодов онтогенеза, ее значение для теории и практики физического воспитания / А.А. Гужаловский. - М.: Физкультура и спорт, 1984. - С. 211-223.

3. Дорохов Р.Н. Спортивная морфология: учебное пособие для высших и средних учебных заведений физической культуры / Р.Н. Дорохов, В.П. Губа. — М.: СпортАкадемПресс, 2002. - 236 с.

4. Есаков С.А. Возрастная анатомия и физиология (курс лекций) /УдГУ. Ижевск, 2010.

5. Приказ Министерства спорта РФ от 20 августа 2019 г. № 675 «06 утверждении федерального стандарта спортивной подготовки по виду спорта «художественная гимнастика»

6. Псеунок А.А., Возрастная анатомия и физиология (лекции). - Майкоп: Изд-во АГУ, 2008, - 268 с.

7. Сонькин В.Д. Физиологические закономерности онтогенеза и их возможные приложения к теории физической тренировки / В.Д. Сонькин //Физиология человека. - 2015. - Т. 41. - № 5. - С. 125.

8. Физическое развитие ребенка: учебное пособие К.А. Арутюнян, А.Ф. Бабцева, Е.Б.Романцова. - Благовещенск: Буквица, 2011 - 35 с.

9. Poryo M., Paes L.A., Pickardt T., Bauer U.M.M., Meyer S., Wagenpfeil S., Abdul-Khaliq H.; German Competence Network for Congenital Heart Defects Investigators. Somatic Development in Children with Congenital Heart Defects. J. Pediatr. 2018 Jan;192:136-143.e4. doi: 10.1016/j.jpeds.2017.09.059. PMID: 29246335.

( ) Шувалова Лилия Сергеевна (lilia9292@mail.ru). 